\title{
Trisomy 18: A Difficult Decision for the Family
}

\author{
Atiye Fedakâr ${ }^{1}$, Seval Eren', Elif Özbey Akan', Selahattin Semiz ${ }^{2}$ \\ ${ }^{1}$ The Departments of Pediatrics, Afiyet Hospital, Istanbul, Turkey \\ ${ }^{2}$ The Departments of Radiology, Afiyet Hospital, Istanbul, Turkey \\ Email: "atyfedakar@hotmail.com
}

Received 18 February 2016; accepted 17 March 2016; published 21 March 2016

Copyright (C) 2016 by authors and Scientific Research Publishing Inc.

This work is licensed under the Creative Commons Attribution International License (CC BY).

http://creativecommons.org/licenses/by/4.0/

(c) (i) 0pen Access

\section{Abstract}

Trisomy 18 (Edwards Syndrome) was first reported in 1960 by Edward et al. in a newborn with multiple abnormalities, and is a broad clinical presentation involving more than 130 different abnormalities. Most cases die during the embryonic or fetal life. Only 5\%-10\% of the live-born cases survive the first year of life. Prenatal diagnosis is possible. However, the prenatal detection compels parents to make a difficult decision. After the birth of the baby, it also places a material and moral burden on both the family and the national economy due to multiple congenital abnormalities and limited lifespan. On the other hand, pediatricians experience difficulties in making a decision on interventions, especially cardiac surgery and resuscitation, due to the comorbid abnormalities in the neonatal intensive care units, in which medical ethics arises for discussion. The current study presents a case diagnosed with trisomy 18 by chromosome analysis, who was found to have multiple abnormalities with ultrasonography (USG) during the prenatal period and born because the patient's mother, who was advised to have amniocentesis, decided to continue with the pregnancy.

\section{Keywords}

Trisomy 18, Prenatal Diagnosis

\section{Introduction}

Trisomy 18 was first described in 1960 by Edward et al. in a newborn with multiple abnormalities and cognitive deficiency. Later in the same year, Smith et al. demonstrated additional chromosomes to the 18th chromosome. Initially known as trisomy 17 - 18 (new trisomy), this syndrome is the second most common syndrome after

${ }^{*}$ Corresponding author. 
Down syndrome, among autosomal trisomies [1]-[3]. It is important because of its high prevalence. It is estimated to occur in 1/3600 - 1/8500 live births in different regions of the world such as North America, Europe, and Australia. It is two times more common in females [2]-[7].

Most cases die during the embryonic or fetal life. The average lifespan is 2.5 - 14.5 days. Prenatal diagnosis is possible. However, the prenatal detection compels parents to make a difficult decision.

The current study presents a case diagnosed with trisomy 18 by chromosome analysis, who was found to have multiple abnormalities with USG during the prenatal period and born because the patient's mother, who was advised to have amniocentesis, decided to continue with the pregnancy.

\section{Case Report}

The patient born as a 37-week baby girl via cesarean delivery from the third pregnancy of a 36-year-old mother was transferred to the neonatal intensive care unit due to respiratory distress. The mother had a history of using antibiotics during her pregnancy due to a urinary tract infection and tooth infection. The mother had been advised at her pregnancy follow-ups to have amniocentesis because of microcephaly and intrauterine growth retardation, but the family did not accept this procedure. At the physical examination, the weight was $1740 \mathrm{~g} \mathrm{(}<3 \%$ percentile), head circumference was $30 \mathrm{~cm}(<3 \%$ percentile), and height was $39 \mathrm{~cm}(<3 \%$ percentile). There were bilateral low-set ears, micrognathia, short neck, flexion of the fingers of both hands and finger overlaps, outwardly prominent heels, and clitoromegaly (Figures 1-3). Gluteal muscles were atrophic. At the cardiac ex-

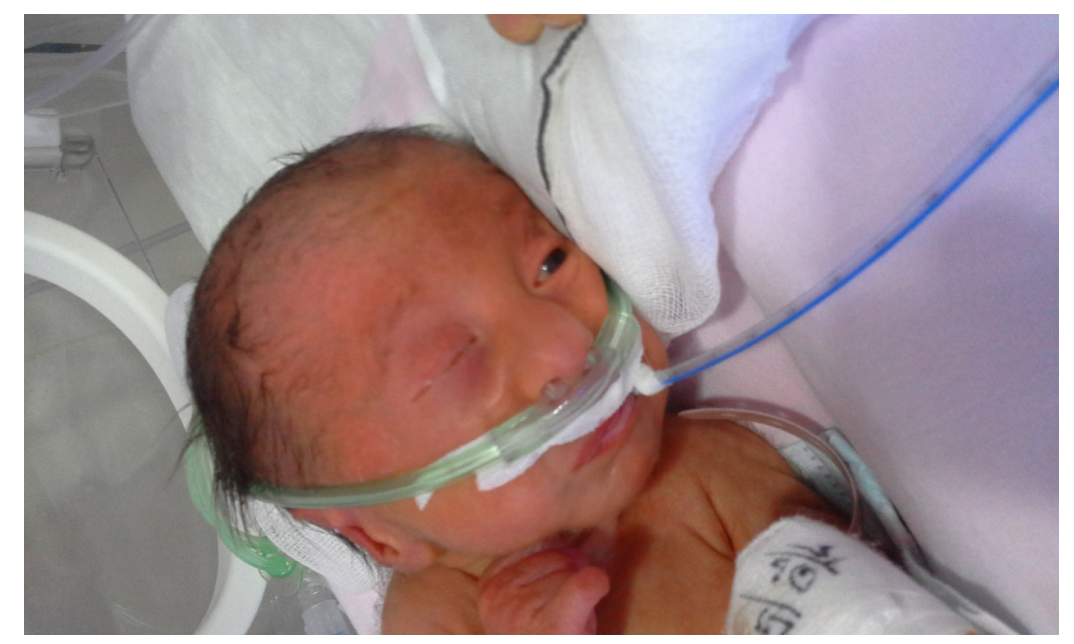

Figure 1. General appearance of a trisomy 18 patient.

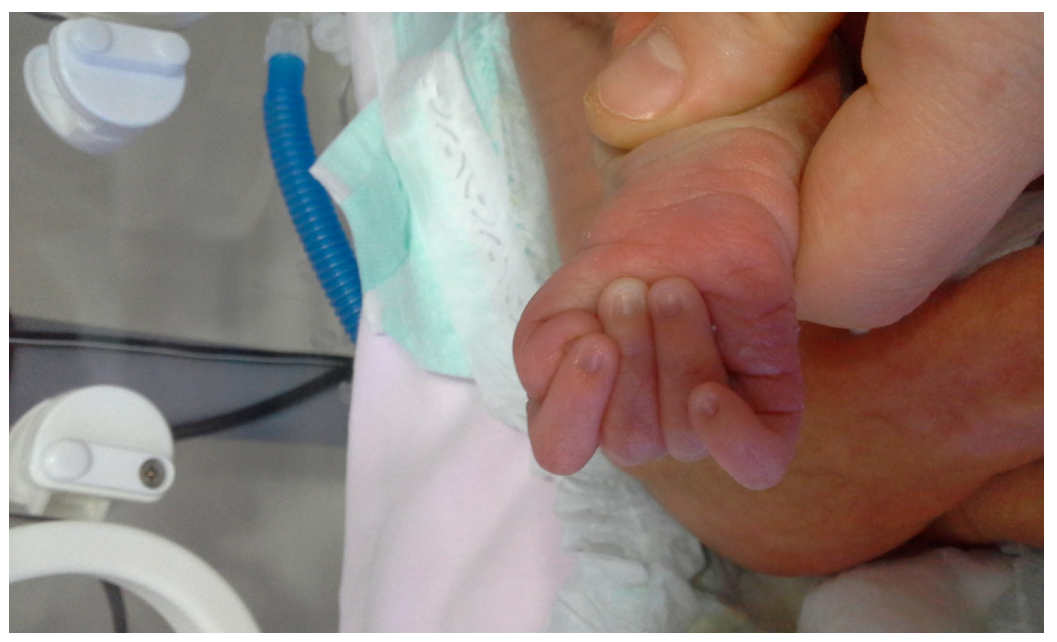

Figure 2. Flexion of fingers and finger overlapping in a trisomy 18 patient. 


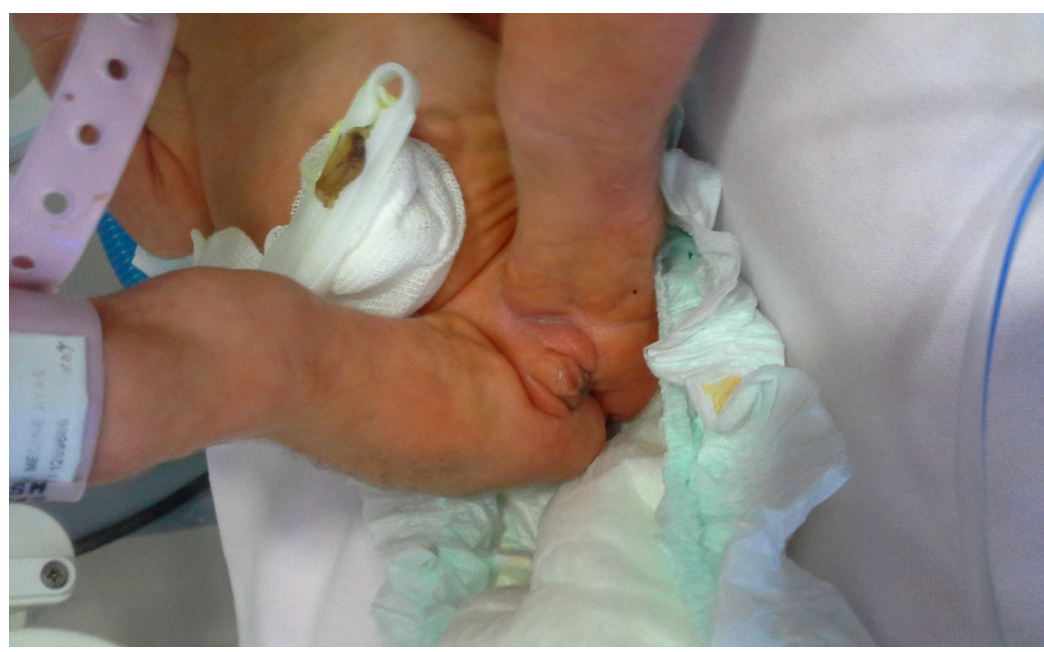

Figure 3. Clitoromegaly in a trisomy 18 patient.

amination, KTA: 120/min sulf was not heard. Due to multiple abnormalities, echocardiography (ECHO) was requested. The laboratory examination revealed normal whole blood count, and kidney and liver function tests. Vitamin D levels were studied in the biochemistry tests due to hypocalcemia. The level of 25-(OH)-vitamin D was $15.98 \mathrm{nmol} / \mathrm{L}$. Chromosome analysis revealed $47 \mathrm{XX}+18$. Abdominal USG was considered normal. The ECHO assessment revealed patent ductus, bicuspid aorta, pulmonary hypertension, and ventricular septal defect (VSD).

The patient who was transferred to the neonatal intensive care unit due to respiratory distress was administered nasal CPAP + IV fluid + antibiotic + vitamin D deficiency treatment. She was followed-up by administering $\mathrm{O} 2$ with CPAP for 13 days and hood for ten days. She was discharged on day 42. She was hospitalized three more times due to bronchopneumonia one week after the discharge. The patient, who is 7.5 months old now, is still being followed-up at the polyclinic.

\section{Discussion}

Trisomy 18 is a syndrome with a very limited prognosis, involving more than 130 different abnormalities in the literature and affecting almost all organs and systems, none of which are pathognomonic [2]. In the etiology, it is caused by the incomplete disjunction of the 18th chromosome during the meiosis of the parents' germ cells. Several studies in the literature have reported that advanced maternal age, environmental pollution, and low socioeconomic status have an effect on this occurrence. Although advanced maternal age has been reported in multiple studies, trisomy 18 has also been described in young mothers, including those at the age of 20 [8]-[10]. It is twice more common in female babies [2] [4]-[7].

Prenatal diagnosis is possible through cytogenetic examination requested in the presence of pathologies such as increased neck skin thickness, intrauterine growth retardation, polyhydramnios, bilateral choroid plexus cyst, and cardiac abnormalities at the prenatal (USG) examination [11]. Genetic assessment was advised for our patient due to intrauterine growth retardation and microcephaly in the prenatal period; however, the family did not accept the procedure and decided to continue with the pregnancy. Additionally, our patient had a mother with an advanced age, did not have polyhydramnios, the infant was female, and the socioeconomic status was obvious. The incidence of pre-eclampsia in the mothers of trisomy 18 babies has been reported to be $12.5 \%$ - 17\% [2] [7]. The frequency of cesarean delivery is very high like 48\% - 90\% and low Apgar scores at minutes 1 and 5, preterm labor, and low birth weight are common in these babies [2] [7] [12].

Our patient, as reported in the literature, was a 37-week preterm, had low birth weight, born via cesarean delivery, and had low Apgar score (6 at minute 1 and 7 at minute 5).

In trisomy 18 babies, intrauterine growth retardation; micrognathia, microcephaly; low-set ears; gastrointestinal and extremity abnormalities; mental retardation; ocular abnormalities such as glaucoma, microphthalmia and cataract; clitoromegaly; and congenital cardiac abnormalities are common. The appearance of overlapping fingers is typical. The most common congenital abnormalities are VSD, atrial septal defect (ASD), patent ductus 
arteriosus (PDA), and pulmonary hypertension [2] [7]. Lin et al. reported 94\% VSD, 77\% PDA and 68\% ASD in their series of 39 cases and found complex congenital heart defect in 32\% [7]. The ECHO of our patient revealed VSD, mild pulmonary hypertension, patent ductus, and bicuspid aorta, and she is still being followed-up by the cardiology department. Furthermore, she had low birth weight, microcephaly, low-set ears, micrognathia, short neck, finger overlaps, clitoromegaly, and outwardly prominent heels. Gluteal muscles were atrophic. Tüysüz et al. reported a case diagnosed with trisomy 18 by chromosome analysis, who was a 45-day-old baby girl with intrauterine growth retardation, craniofacial dysmorphism, flexion contractures, congenital cardiac abnormality, and clitoromegaly [13].

The survival rate of trisomy 18 cases depends on comorbid abnormalities. The average lifespan is 1.5 - 14.5 days and $95 \%$ of the pregnancies result in embryonic or fetal deaths, whereas only $5 \%$ - $10 \%$ of the live-born cases survive the first year of life. The literature reports the most common causes of mortality as congenital heart diseases, aspiration pneumonia, sepsis, and renal failure [2] [14]. The longest lifespan reported in the literature by now is 50 years [15]. Our patient, after being discharged from the neonatal intensive care unit, was hospitalized three times due to bronchopneumonia. She was frequently treated due to respiratory tract infection during the subsequent follow-ups. Our patient, who is 7.5 months old now, is still being followed-up at the polyclinic.

In conclusion, the combined effects of both genetics and environment are responsible for the etiology of trisomy 18. Prenatal diagnosis is possible. However, the prenatal detection compels parents to make a difficult decision. Therefore, importance is likely to be placed on clarifying and managing etiological factors in future clinical studies.

\section{Financial Disclosure}

There isn’t any financial disclosure.

\section{Conflict of Interest}

The authors declare that they have no conflict of interest.

\section{References}

[1] Edwards, J.H., Harnden, D.G., Cameron, A.H., Crosse, V.M. and Wolff, O.H. (1960) A New Trisomic Syndrome. Lancet, 275, 787-790. http://dx.doi.org/10.1016/S0140-6736(60)90675-9

[2] Rosa, R.F.M., Rosa, R.C.M., Zen, P.R.G., Graziadio, C. and Paskulin, G.A. (2013) Trisomy 18: Review of the Clinical, Etiologic, Prognostic, and Ethical Aspects. Revista paulista de pediatria, 31, 111-120.

[3] Smith, D.W., Patau, K., Therman, E. and Inhorn, S.L. (1960) A New Autosomal Trisomy Syndrome: Multiple Congenital Anomalies Caused by an Extra Chromosome. Journal of Pediatrics, 57, 338-345. http://dx.doi.org/10.1016/S0022-3476(60)80241-7

[4] Rasmussen, S.A., Wong, L.Y., Yang, Q., May, K.M. and Friedman, J.M. (2003) Population-Based Analyses of Mortality in Trisomy 13 and Trisomy 18. Pediatrics, 111, 777-784.

[5] Goldstein, H. and Nielsen, K.G. (1988) Rates and Survival of Individuals with Trisomy 13 and 18. Data from a 10Year Period in Denmark. Clinical Genetics, 34, 366-372. http://dx.doi.org/10.1111/j.1399-0004.1988.tb02894.x

[6] Weber, W.W. (1967) Survival and the Sex Ratio in Trisomy 17-18. The American Journal of Human Genetics, 19, 369-377.

[7] Lin, H.Y., Lin, S.P., Chen, Y.J., Hung, H.Y., Kao, H.A., Hsu, C.H., et al. (2006) Clinical Characteristics and Survival of Trisomy 18 in a Medical Center in Taipei, 1988-2004. American Journal of Medical Genetics Part A, 140, 945-951. http://dx.doi.org/10.1002/ajmg.a.31173

[8] Kelly, M., Robinson, B.W. and Moore, J.W. (2002) Trisomy 18 in a 20-Year-Old Woman. American Journal of Medical Genetics, 112, 397-399. http://dx.doi.org/10.1002/ajmg.10638

[9] Naguib, K.K., Al-Awadi, S.A., Bastaki, L., Moussa, M.A., Abulhassan, S.A., Tayel, S., et al. (1999) Clustering of Trisomy 18 in Kuwait: Genetic Predisposition or Environmental? Annals of Saudi Medicine, 19, 197-200.

[10] Nussbaum, R., McInnes, R., Willard, H. and Boerkoei, C. (2004) Principles of Clinical Cytogenetics. Thompson and Thompson Genetics in Medicine. Saunders, Philadelphia, 135-154.

[11] Niedrist, D., Riegel, M., Achermann, J. and Schinzel, A. (2006) Survival with Trisomy 18—Data from Switzerland. American Journal of Medical Genetics Part A, 140A, 952-959. http://dx.doi.org/10.1002/ajmg.a.31172 
[12] Young, I.D., Cook, J.P. and Mehta, L. (1986) Changing Demography of Trisomy 18. Archives of Disease in Childhood, 61, 1035-1036. http://dx.doi.org/10.1136/adc.61.10.1035

[13] Tüysüz, B., Yanar, U., Özgür, B., Erginel, A. and Cenani, A. (1996) Trisomi 18 (Edwards) Sendromu. Türk Pediatri Arşivi, 31, 293-296.

[14] Carey, J.C. (2005) Trisomy 18 and Trisomy 13 Syndromes. In: Cassidy, S. and Allanson, J., Eds., Management of Genetic Syndromes, John Wiley \& Sons, Inc., Hoboken. http://dx.doi.org/10.1002/0471695998.mgs047

[15] Bhanumathi, B., Neelam, A.G. and Mishro, Z.A. (2006) Trisomy 18 in a 50-Year-Old Female. Indian Journal of Human Genetics, 12, 146-147. http://dx.doi.org/10.4103/0971-6866.29860 